\title{
Emission tests of the F100-PW-229 turbine jet engine during pre-flight verification of the F-16 aircraft
}

\author{
J. Merkisz, J. Markowski \& J. Pielecha \\ Poznan University of Technology, Poland
}

\begin{abstract}
The operation of military aircraft is associated with the realization of objectives that are connected with national defence. Particular importance is attributed to the defence of national borders and airspace. In the realization of the above, one of the best are multirole jet fighter planes such as F16. A continuous readiness of the aircraft to perform the military tasks requires certain diagnostic procedures that verify their condition. One of them is a pre-flight trial during which the functioning of all aircraft components, including the power train is tested. The testing of the engine consists in the evaluation of several parameters for the assumed setting of the power lever and allows evaluating the operational capability as regards the realization of the flight. However, it is impossible to retrieve information on the condition of the engine. Hence, it seems reasonable to introduce an additional procedure enabling the determination of the concentrations of the exhaust emission components in order to monitor the aircraft engine condition. The paper presents the results of research on the exhaust emissions from a multirole F16 aircraft during the pre-flight trial. The aim of this project was to verify the possibilities of measurement of the exhaust emissions during the trial, the evaluation of the exhaust emissions at varied power lever settings and the obtainment of the preliminary data for the evaluation of the exhaust emissions during tests under aircraft actual operating conditions. The obtained data were used for the calculation of the relations characterizing the influence of the operating parameters of the engine on the exhaust emissions. The paper presents the results of the tests and their analyses allowing an evaluation of the possibilities of application of this type of stationary tests for the determination of the exhaust emissions from turbine jet engines.

Keywords: exhaust emissions, turbine jet engines.
\end{abstract}




\section{Introduction}

Poland as a NATO member state is under an obligation to modernize its army. This modernization is carried out in all types of armed forces of the Republic of Poland. Particularly conspicuous are the projects realized in the Air Force. Such actions are a result of a variety of global expectations reflected in the currently realized tasks in the Polish Air Force. The main task of the Polish Air Force is readiness to perform activity in the NATO structure. The tasks pertain to air transport in particular. Tactical Air Force is mostly targeted at defense of the Polish airspace. This activity is of high political importance as Poland is a country whose east border is the border of the European Union. Poland's geopolitical situation requires maintaining tactical Air Force and its constant modernization. The investments in new aircraft are related to maintaining high combat readiness and high operational reliability of the fighter planes. In order to ensure these two parameters it is necessary to maintain the operational readiness of the fighter planes and high level of expertise of the pilots in the time of piece. Hence, majority of the operating time of the planes is devoted to pilot training. The operating conditions of fighter planes used in the training are much different from those in combat missions. Hence, validation of the actual impact of the fighter planes on the natural environment seems purposeful [1].

The realization of the exhaust emission tests on aircraft engines in stationary conditions can be used to develop algorithms that allow an evaluation of the actual emission level from aircraft thus adding to further improvement of the aircraft propulsion systems.

\section{Research methodology}

The investigations into the exhaust emissions of a jet engine were carried out on an F-16 Fighting Falcon (Fig. 1) whose powertrain is based on a turbofan jet engine F100-PW-229 (Fig. 2). The parameters of the F-16 engine have been shown in table 1. One of the elements of the tested aircraft is the flight recorder that also recoded the engine operating parameters.

Table 1: $\quad$ Characteristics F100-PW-229 Engine [4].

\begin{tabular}{|c|c|}
\hline Thrust & $23.770-29.160 \mathrm{lb}$ \\
\hline Weight & $3.740 \mathrm{lb}$ \\
\hline Length & $191 \mathrm{in}$ \\
\hline Inlet Diameter & $34.8 \mathrm{in}$ \\
\hline Maximum Diameter & $46.5 \mathrm{in}$ \\
\hline Overall Pressure Ratio & 32 to 1 \\
\hline
\end{tabular}




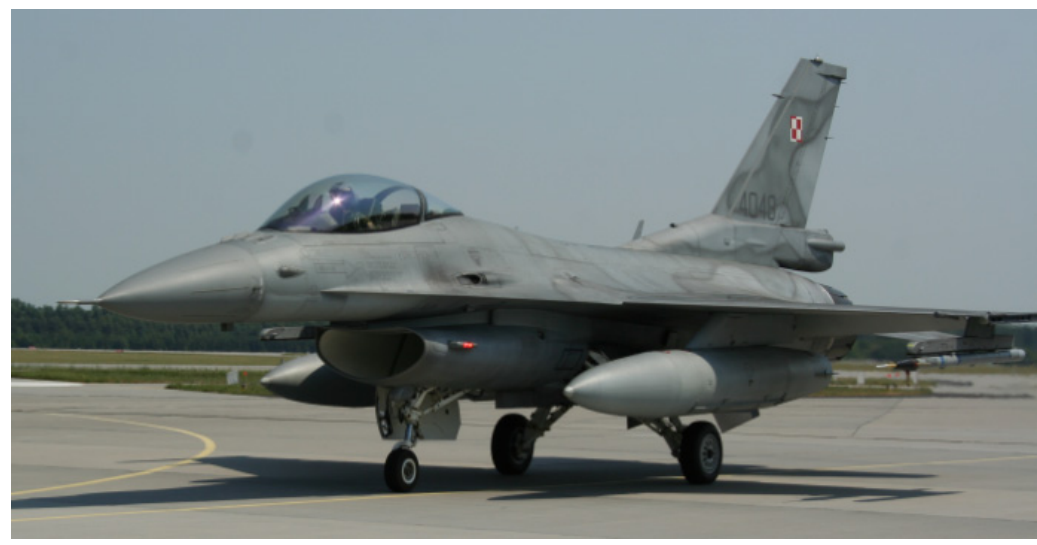

Figure 1: F-16 aircraft.

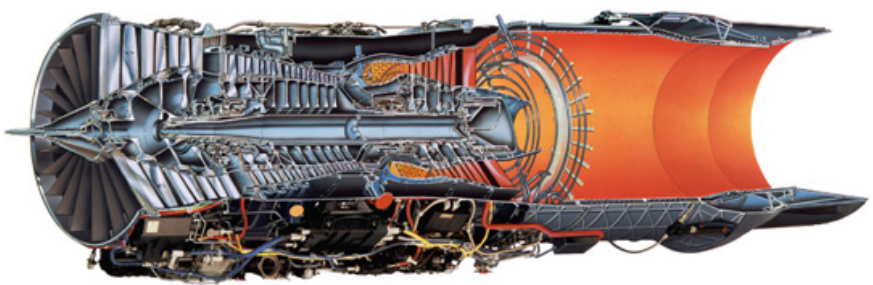

Figure 2: Turbine jet engine F100-PW-229 [4].

The aim of the performed tests was to assess the exhaust emission level from a stationary aircraft on the apron under the conditions closest to the real operating conditions of the fighter plane. For the measurements of the concentrations of the exhaust components the authors used a portable exhaust emission analyzer SEMTECH DS by SENSORS (Fig. 3).

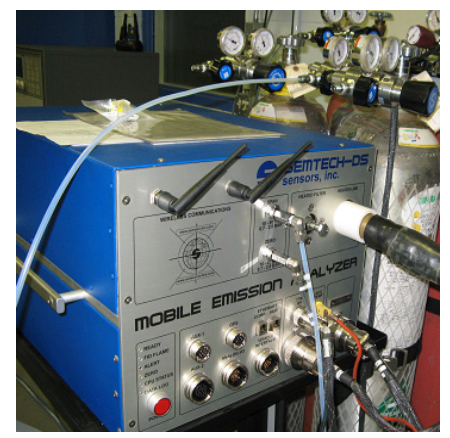

Figure 3: View of the exhaust emission analyzer. 
The analyzer measured the concentration of carbon monoxide, carbon dioxide, hydrocarbons, nitric oxides and oxygen. The exhaust gases were introduced into the analyzer through a measuring probe that maintained the temperature of $191{ }^{\circ} \mathrm{C}$ and then were filtered out of the particulate matter (only in the case of diesel engines) and the concentration of hydrocarbons was measured through a flame ionization detector. Next, the exhaust was cooled down to the temperature of $4^{\circ} \mathrm{C}$ and the concentrations of the following were measured respectively $\mathrm{NO}_{\mathrm{x}}, \mathrm{CO}, \mathrm{CO}_{2}$ and oxygen [2].

For the purpose of the emission measurements the authors fitted additional supports near the engine exhaust to facilitate fixing of the measuring probe. The lines feeding the exhaust gas to the analyzer were fixed to a specially designed support and the analyzer itself was placed at a safe distance from the engine (Fig. 4).

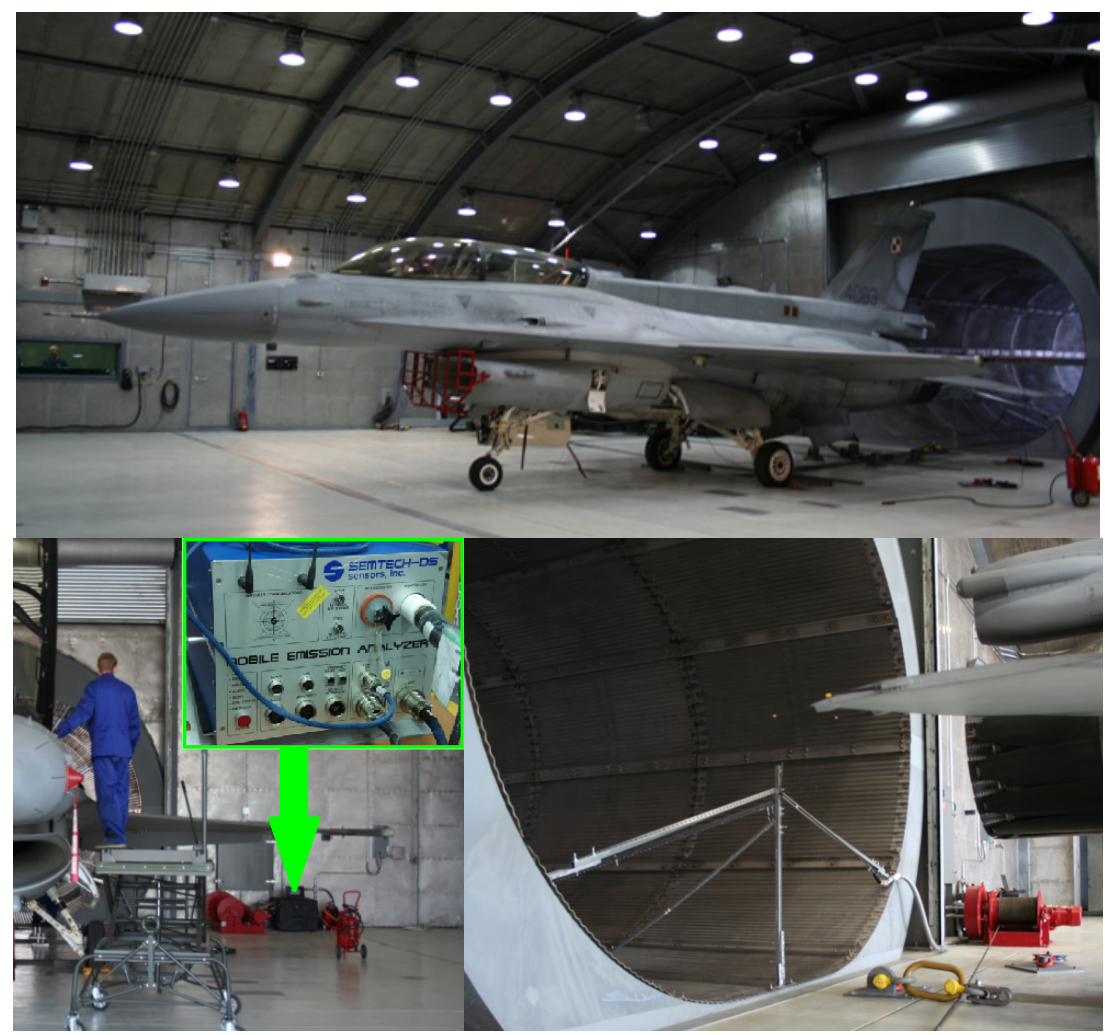

Figure 4: Location of the measuring probe and the analyzer.

The aim of the performed investigations was to measure the exhaust emissions from a turbofan jet engine fitted in the F-16 fighter plane. The measurements of the concentrations were performed on a continuous basis maintaining engine parameters that reflected the operating parameters at a pre- 
flight engine trial [3]. During the tests the measurements of carbon monoxide, carbon dioxide hydrocarbons and nitric oxides were performed. The authors decided on measurements at the operating parameters of the pre-flight engine trial as this trial is imposed by the engine manufacturer and is obligatory for the proper validation of the technical condition of the engine and the aircraft before service. The pre-flight engine trail is realized according to the instructions recommended by the engine manufacturer. The course of the trail and the values of the individual engine parameters were recorded by a recording device fitted in the aircraft.

\section{Measurement results}

The operating parameters of the power train were recorded as a function of time and a continuous measurement of the concentrations of selected exhaust components was carried out. Thanks to that certain phases of the engine trial could be synchronized with the emission measurements of the emissions of the individual exhaust components. The changes in the recorded parameters have been presented in graphs in figure 5. The performed analysis of the changes of the parameters related to the realization procedure of the pre-flight engine trial led to distinguishing of the individual load phases of the engine.

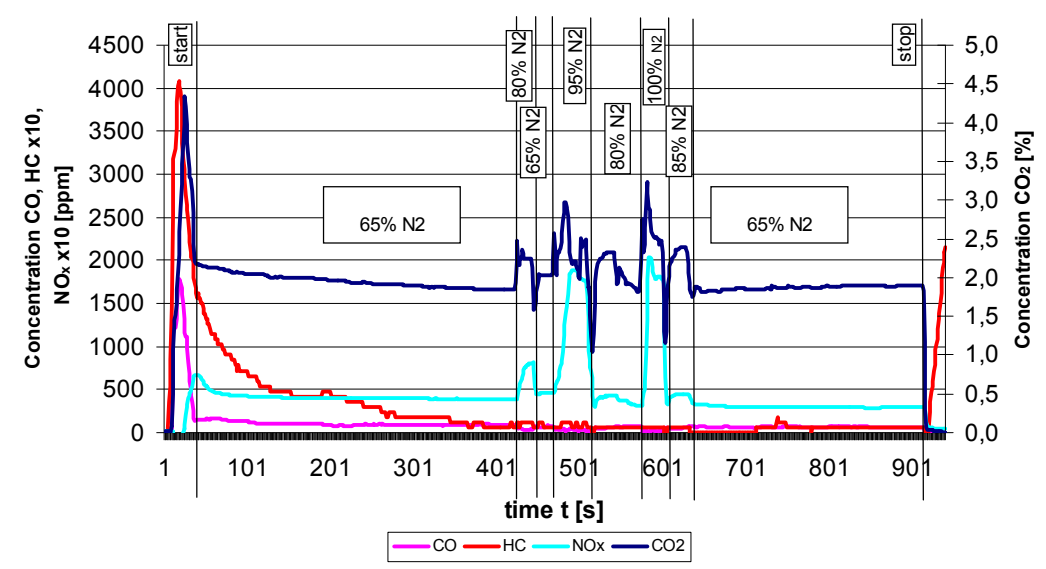

Figure 5: Results of the measurements of the concentrations of the exhaust components as a function of time during the pre-flight engine trial F100-PW-229.

In the graph, vertical lines show the individual phases of the pre-flight engine trial along with a percentage index of the engine load. For the turbine engine characteristic is the beginning of the start-up phase. In this part we can see a high concentration of hydrocarbons that is directly related to the fuel feed to the combustor. Then, as the ignition is initiated in the combustor the concentrations of $\mathrm{CO}, \mathrm{CO}_{2}$ and also $\mathrm{HC}$ grow rapidly. The increase in the concentration of these 
components is a consequence of the combustion process that is not very efficient in the initial phase. The concentrations of these components drop rapidly as the combustor warms up and the other engine elements obtain a proper thermal state.

The heating up of the combustor leads to the growth in the $\mathrm{NO}_{\mathrm{x}}$ concentration in the exhaust. As the engine temperature grows the concentration of nitric oxides stabilizes on the level of $50 \mathrm{ppm}$ at the engine load of approximately $65 \%$ of the maximum turbine speed (N2 turbine shaft speed). As the turbine speed grows (engine load grows) to $80 \%$ of the maximum speed, the concentration of $\mathrm{NO}_{\mathrm{x}}$ in the exhaust amounts to approximately $80 \mathrm{ppm}$. The growth of the turbine speed to $95 \%$ of the maximum speed results in a growth of the $\mathrm{NO}_{\mathrm{x}}$ concentration in the exhaust to approximately $200 \mathrm{ppm}$. A similar nature of changes we can observe for carbon dioxide. The maximum values of the $\mathrm{CO}_{2}$ concentration at individual operating points are respectively: for $65 \%$ of the maximum turbine speed- approximately $2 \% \mathrm{CO}_{2}$, for $80 \% \mathrm{~N} 2-2.5 \% \mathrm{CO}_{2}$, and for $100 \% \mathrm{~N} 2-3.5 \% \mathrm{CO}_{2}$. The concentration of carbon monoxide in the exhaust reaches its maximum value of $1700 \mathrm{ppm}$ in the initial phase of the engine startup after the ignition initiates in the combustor. Then it drops rapidly and remains on the level of 50-100 ppm. The course of the concentration changes is similar. The maximum values of $\mathrm{HC}-400 \mathrm{ppm}$ occur at the moment of start-up and then as the combustor warms up and the engine reaches the desired thermal state the hydrocarbon concentration drops to approximately $15 \mathrm{ppm}$. The concentration of hydrocarbons grows again when the engine is turned off and reaches $200 \mathrm{ppm}$. The growth of the hydrocarbons concentration is a result of an evaporation of the fuel remains from the combustor. Relatively low concentrations of the individual exhaust components are related to a high excess air coefficient in the combustor, which, in the case of turbine engines results in exhaust dilution.

\section{Analysis of the engine parameters under conditions of actual operation}

The authors conducted an analysis of data recorded by the flight recorders from several patrol and training flights. An example tracing of the engine operating parameters recorded during one of the flights has been shown in figure 6 . The authors performed a statistical analysis of selected engine operating parameters from 10 flights. The obtained courses of the values of average analyzed parameters indicate that the engine of the multirole F-16 aircraft was operated in the range of the N2 shaft speed from approx. $70 \%$ to $100 \%$ of the maximum speed, the N1 shaft speed from $40 \%$ to approx. $105 \%$ of the maximum speed. The opening (\%) of the exhaust nozzle and the fuel consumption provides information on the instantaneous engine load. 


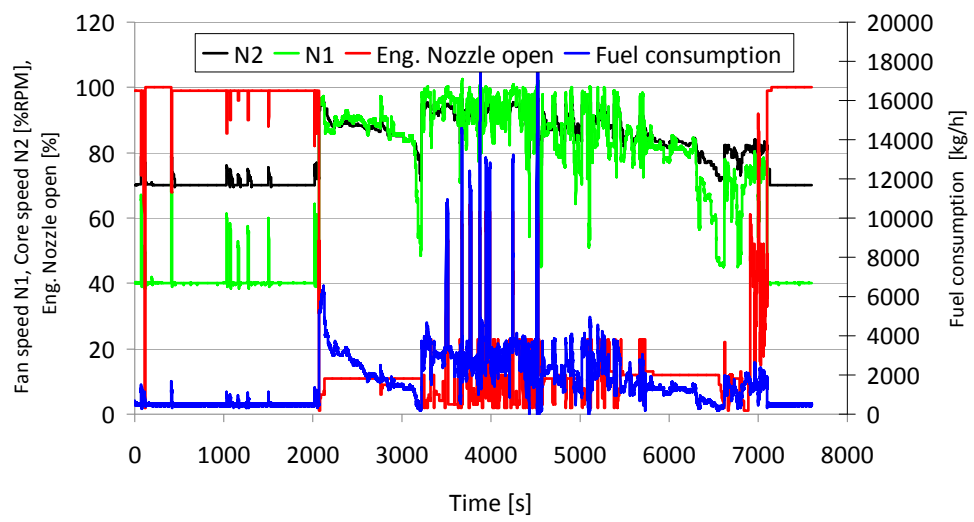

Figure 6: Example tracing of the operating parameters of the F100-PW-229 engine recorded during the flight of the F-16 aircraft.

The distribution of the analyzed parameters in the operating area of the engine (Fig. 7) provides a possibility of determining of the engine fields of work. Particularly conspicuous is the engine field of work when the afterburner is used. This field can be defined with the fuel consumption from approx. $6000 \mathrm{~kg} / \mathrm{h}$ to approx. $18000 \mathrm{~kg} / \mathrm{h}$. From the point of view of the exhaust emissions this area is very significant, yet because of no reference of the measurements to the stationary measurements performed on the test stand in the proposed test it will be omitted. Another step in the attempt to develop a turbine aircraft exhaust emissions measurement test is the determination of the operating time share of the engine at individual ranges of loads. Then we need to determine the test phases and their share in the algorithm of determination of the individual exhaust components.

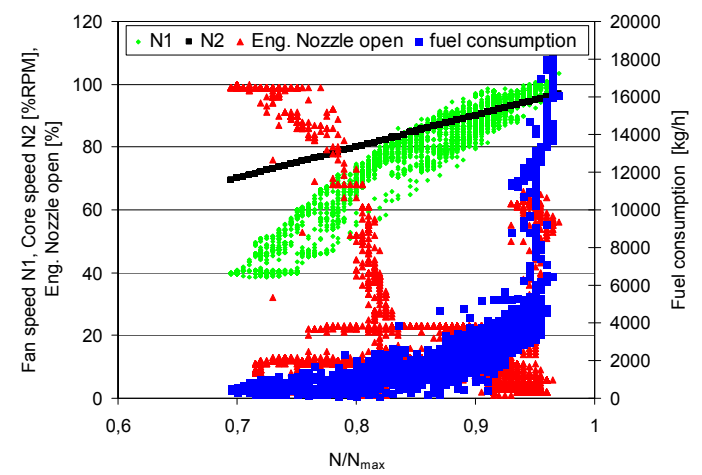

Figure 7: Distribution of the analyzed parameters in the operating area of the F100-PW-229 engine during the flight of the F-16 aircraft. 


\section{A proposal of a measurement test for the evaluation of the exhaust emissions level from the F-16 aircraft}

The knowledge of the operating criteria of a turbine engines allows a development of a universal measurement test of the exhaust emissions generated by aircraft engines. The development of the test and its implementation in the diagnostic procedures could contribute to the reduction of the consumption of time and labor related to the testing of the engine technical condition. To this end the authors have undertaken to develop a measurement test adopting the following assumptions:

- The test should be representative of all multirole aircraft powered by turbine jet engines; the exhaust emissions test results obtained during a stationary test should be similar to the results obtained during testing under actual operating conditions;

- The number of the test phases should not exceed 3 and their selection should be based on the load parameters close to those most frequently used when in service (engine idling phase, part loads and maximum load);

- The test should remain within the scope of the aircraft pre-flight trials.

The third of the listed assumption is very important because the duration of the pre-flight trial is included in the service time of the aircraft engine. Hence, it is advisable that the test duration does not reduce the service life.

For the construction of the tests as input data the authors used the recorded tracings of the operating parameters of selected flights. The available data upon initial statistical processing were initially divided into 5 ranges of the second stage turbine shaft speed. The adopted turbine speed ranges N2 were 70-80, 5\% N2 max., 81-85.5\% N2 max., 86-90.5\% N2 max., 91-95\% N2 max. and 96$100 \%$ N2 max. For these ranges of the N2 shaft speed the operating time shares were determined. The operating time shares in the total flight duration for the individual ranges are as follows: for $70-80.5 \% \mathrm{~N} 2 \max .-12.82 \%, 81-85.5 \% \mathrm{~N} 2$ $\max .-26.39 \%, 86-90.5 \% \mathrm{~N} 2$ max. $-30.29 \%$, 91-95\% N2 max. $-29.57 \%$ and for $96-100 \%$ N2 max. $-0.93 \%$. Minding the necessary simplicity of the test the authors assumed that the test should be composed of three phases. Hence, the authors merged the previously determined ranges $\mathrm{N} 2$ obtaining $70-80.5 \% \mathrm{~N} 2$ max. $-12.82 \%, 81-90.5 \%$ N2 $\max .-56.69 \%, 91-100 \%$ N2 max. $-30.49 \%$. In this way the test points were determined at individual settings of the operating parameters and with an appropriate share of the phase in the exhaust emissions (tab. 2). The graphical representation of the adopted tests has been shown in figure 8 .

Table 2: $\quad$ Characteristics of the test phases and their weighted share.

\begin{tabular}{|c|c|c|c|}
\hline Phase & $\mathrm{A}$ & $\mathrm{B}$ & $\mathrm{C}$ \\
\hline $\mathrm{N} 2 / \mathrm{N} 2_{\max }$ & 0.75 & 0.85 & 0.93 \\
\hline $\mathrm{K} / \mathrm{Kn}$ & 0.75 & 0.85 & 0.93 \\
\hline Phase share & 13 & 57 & 30 \\
\hline
\end{tabular}




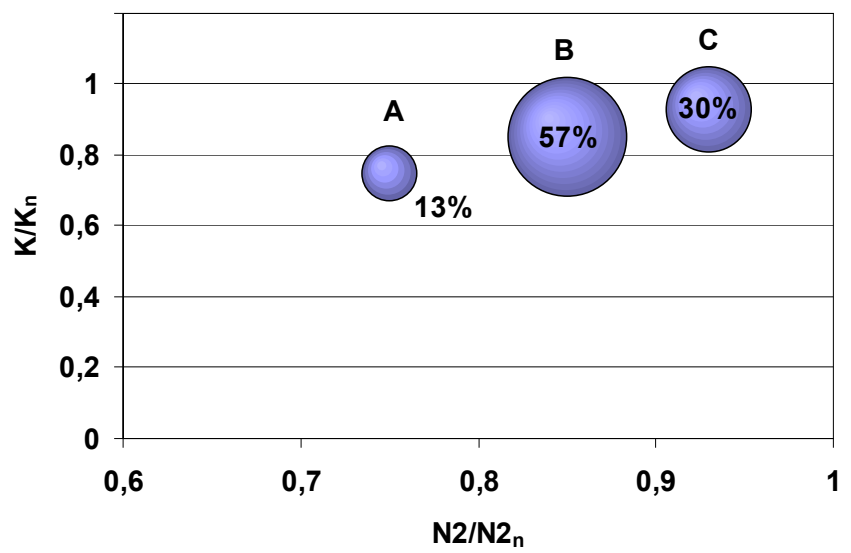

Figure 8: Characteristics of the phases and their share in the proposed stationary universal test for multirole aircraft turbine engines.

Knowing the average shares of the individual phases in the total flight time (tab. 2), totaling the value of the product of the exhaust emission in the individual flight phase and the percentage share of the phase we can determine the emission values of the individual exhaust components during the whole flight using the formula:

$$
\mathrm{E}_{\mathrm{j}}=\sum \mathrm{E}_{\mathrm{ji}} \cdot \mathrm{u}_{\mathrm{i}}[\mathrm{g}]
$$

where:

$\mathrm{E}_{\mathrm{ji}}$ - unit emission for a given load [g],

$\mathrm{u}_{\mathrm{i}}-$ load time share during the trial $[-]$.

\section{The attempt to determine the exhaust emissions in the proposed test}

For the determination of the exhaust emissions generated by the turbine jet engine it is necessary in the proposed test to determine the exhaust gas outflow at the operating parameters determined for the test phases. The value of the exhaust gas mass flow and the information on the concentration of the individual exhaust components contained in it enables a determination of the emission of these components. The exhaust gas flow leaving the engine was determined based on the excess air coefficient measured at the axis of the exhaust gas flow (Fig. 9). 


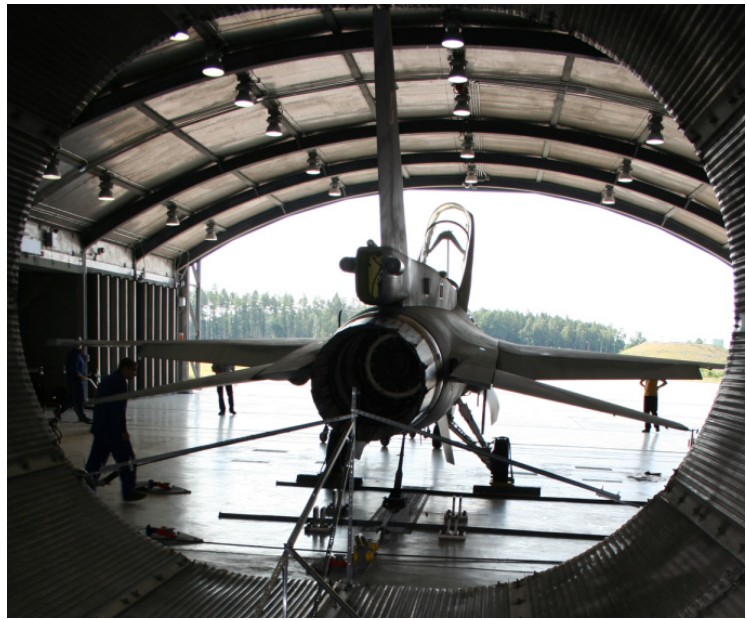

Figure 9: Location of the measurement probe in the axis of the exhaust gas flow leaving the engine.

For a complete combustion of a kilogram of fuel we need approximately 14 kilograms of air and for these conditions of the realization of combustion the excess air coefficient is 1 . Measuring the value of the excess air coefficient in the exhaust gas and the fuel consumption at a given operating point we can determine the amount of exhaust gas flowing out of the engine. The value of the excess air coefficient in the exhaust gas, the fuel consumption and the calculated exhaust mass flow for the individual operating points of the engine have been shown in table 3 . This table also contains the concentrations of the individual exhaust components in the operating points determined for the test phases.

Table 3: The values of the excess air coefficient in the exhaust gas, fuel consumption, exhaust gas flow and concentration of the exhaust components for the parameters determined for the test phases.

\begin{tabular}{|l|c|c|c|}
\hline Phase & A & B & C \\
\hline Excess air coefficient [-] & 8 & 7 & 5 \\
\hline Fuel consumption $[\mathrm{kg} / \mathrm{s}]$ & 0.168 & 0.199 & 1.711 \\
\hline Exhaust mass flow [kg/s] & 18.832 & 22.324 & 167.688 \\
\hline Concentration of $\mathrm{CO}_{2}$ in the exhaust gas [\%] & 2.0 & 2.3 & 2.6 \\
\hline Concentration of $\mathrm{CO}$ in the exhaust gas [ppm] & 80 & 80 & 75 \\
\hline Concentration of $\mathrm{HC}_{\text {in the exhaust gas [ppm] }}$ & 15 & 15 & 15 \\
\hline $\begin{array}{l}\text { Concentration of } \mathrm{NO}_{\mathrm{x}} \text { in the exhaust gas } \\
\text { [ppm] }\end{array}$ & 40 & 70 & 200 \\
\hline
\end{tabular}


Knowing the exhaust mass flow and the concentration of the exhaust components the authors determined the exhaust emission rate during the operation of the engine in individual operating points (table 4).

Table 4: Exhaust emission rate for the parameters determined for the test phases.

\begin{tabular}{|l|c|c|c|}
\hline Phase & $\mathrm{A}$ & $\mathrm{B}$ & $\mathrm{C}$ \\
\hline The emission rate of $\mathrm{CO}_{2}[\mathrm{~g} / \mathrm{s}]$ & 376.6 & 513.5 & 4359.9 \\
\hline The emission rate of $\mathrm{CO}[\mathrm{g} / \mathrm{s}]$ & 0.0151 & 0.0179 & 0.1258 \\
\hline The emission rate of $\mathrm{HC}[\mathrm{g} / \mathrm{s}]$ & 0.0028 & 0.0033 & 0.0252 \\
\hline The emission rate of $\mathrm{NO}_{\mathrm{x}}[\mathrm{g} / \mathrm{s}]$ & 0.0075 & 0.0156 & 0.3354 \\
\hline
\end{tabular}

Using the previously presented equation (1) the calculations were performed of the values of the exhaust emissions for the developed measurement test related to the actual operating conditions of the F-16 aircraft. The products of the exhaust emission rates and the operating time shares of the individual phases were summed up. The obtained results have been presented in figure 9. The exhaust emissions measured during the proposed test was: for $\mathrm{CO}_{2}-164959.7 \mathrm{~g}$, for $\mathrm{CO}-4.99 \mathrm{~g}$, for $\mathrm{HC}-0.98 \mathrm{~g}$ and for $\mathrm{NO}_{\mathrm{x}}-11.05 \mathrm{~g}$.

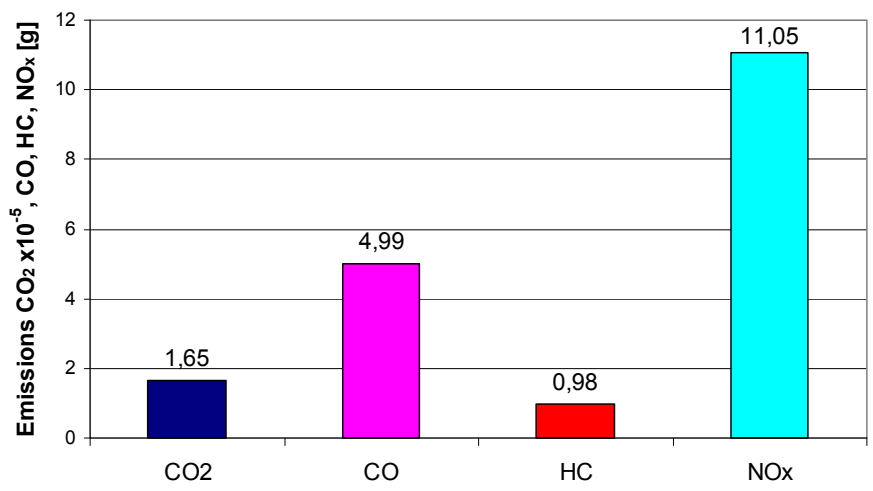

Figure 10: The exhaust emissions measured in the proposed tests.

\section{Conclusions}

The conducted tests and analyses of the actual operating conditions of a multirole aircraft confirm the significant differences in the energy related and ecological properties of the powertrains. The differences are very significant when considering the engine level of deterioration. Hence, the authors are seeking a non-invasive solution to verify the engine technical condition that will be applicable without taking the plane out of service. To this end the authors proposed a stationary exhaust emission test realizable during the pre-flight 
aircraft trials. These trials contain in their procedure operating ranges fairly well corresponding to the actual engine loads during the flight and they could be deemed representative for the measurement of the exhaust emissions under actual conditions of operation. When validating the test and determining of the exhaust emissions during the test we seek boundary values that will in the future serve as a criterion for the admission of an aircraft for service.

\section{References}

[1] Kotlarz W., Turbinowe zespoły napędowe źródtem skażeń powietrza na lotniskach wojskowych. Wyższa Szkoła Oficerska Sił Powietrznych, Dęblin 2003.

[2] Kotlarz W., Piaseczny L., Rypulak A., Zadrąg R., Tests of exhaust gas toxicity of jet turbine engine for take off and landing phases of flight. Cambustion Engines, No. 4, 2006.

[3] Orkisz M.: Podstawy doboru turbinowych silników odrzutowych do płatowca. Biblioteka Naukowa Instytutu Lotnictwa, Warszawa 2002.

[4] Wygonik P., Selection criteria of turbine engine parameters for multipurpose aircraft. Combustion Engines, No. 4, 2006.

[5] Merkisz J., Markowski J., Pielecha J., The Exhaust Emission Tests of a Zlin142 M Aircraft. Cambustion Engines, No. 2, 2011.

[6] Annex 16 to the Convention on International Civil Aviation International Civil Aviation Organization, Volume II.

[7] http://en.wikipedia.org/wiki/Pratt_\%26_Whitney_F100 